\title{
Maldives
}

\section{Awarding bodies}

Maldives College of Higher Education

Accrediting agencies

Maldives Accreditation Board

\section{Key facts}

Population: 0.31 million (CEP 2007)

Education expenditure: $3.7 \%$ of the GDP in 2001/2 (CEP 2007)

Primary enrolment: 92\% (CEP 2007)

Secondary enrolment: 51\% (CEP 2007)

Tertiary enrolment: $\mathrm{n} / \mathrm{a}$

Number of primary teachers: 3,463 in 2009 (self-reported)

Number of secondary teachers: 2,897 in 2009 (self-reported)

Estimated number of un- and underqualified teachers: 1,283 in 2009 (selfreported)

Estimated number of foreign teachers: 152 in 2009 (self-reported)

\section{Professional requirements for teaching}

Minimum qualification

Annual fees

\section{Key contacts}

Ministry of Education

Ms Fathmath Fazeela

f.fazeela@moe.gov.mv

+960 7777640 (t)

+960 3315254 (f)

Maldives Accreditation Board

Mr Abdul Hannan Waheed

hannan@mab.gov.mv 


\section{Initial Primary Teaching Qualifications}

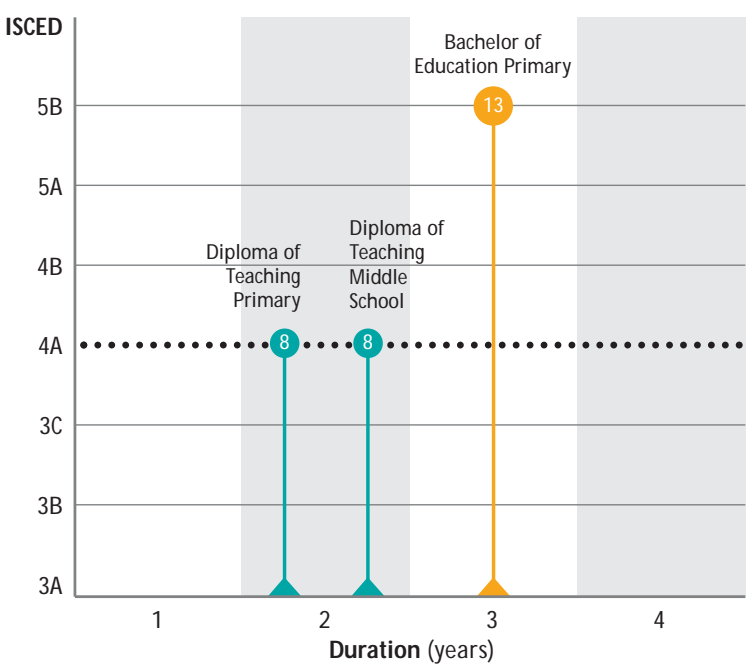

\section{Notes}

1 Minimum standard for teaching at primary level: ISCED 4

2 B Ed entry requires at least 2 years teaching experience

3 Pathway(s):

3.1 Diploma of Teaching Primary $(2,8)$

3.2 Diploma of Teaching Middle School $(2,8)$

3.3 Bachelor of Education Primary $(3,13)$

\section{Initial Secondary Teaching Qualifications}

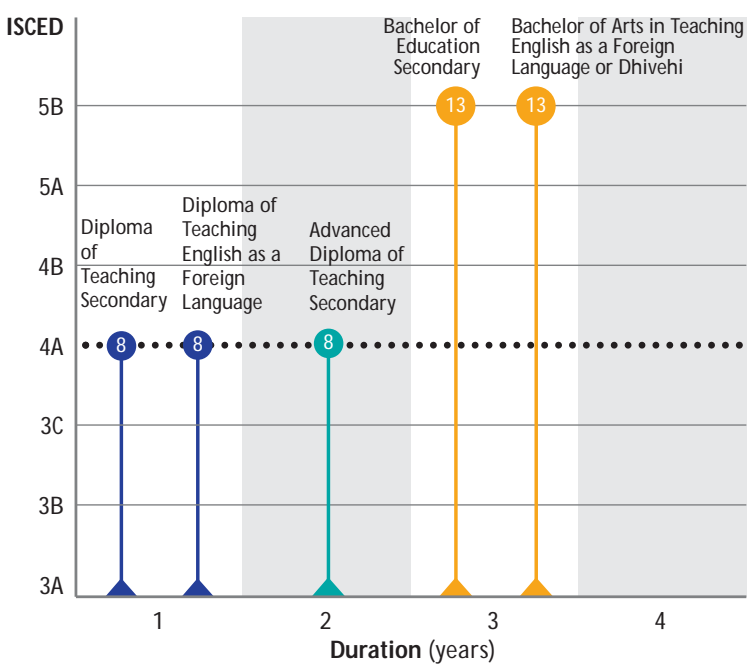

\section{Notes}

1 Minimum standard for teaching at upper secondary level: ISCED 4

2 Pathway(s):

2.1 Diploma of Teaching Secondary $(1,8)$

2.2 Diploma of Teaching English as a Foreign Language $(1,8)$

2.3 Advanced Diploma for Teaching Secondary $(2,8)$

2.4 Bachelor of Education Secondary $(3,13)$

2.5 Bachelor of Arts in Teaching English as a Foreign Language/Dhivehi $(3,13)$ 